\title{
The virtual harvesting prototype design of Long-roots herbal and the motion simulation of key components
}

\author{
HUANG Jin Xia ${ }^{1, a}$, YU Yong Hong ${ }^{2, b}$,GE Yi Yuan ${ }^{2, c}$ and ZHANG Yun Xiang, ${ }^{3, d, *}$ \\ ${ }^{1}$ Institute of Information Electronic Technology, Jiamusi University, Jiamusi, Heilongjiang Province, \\ P. R.China 154007. Email: hjxlcj2006@sina.com \\ ${ }^{2}$ College of Mechanical Engineering, Jiamusi University, Jiamusi, Heilongjiang Province, P. R.China \\ 154007 \\ ${ }^{3}$ Business College, Jiamusi University,Jiamusi ,Heilongjiang Province, P. R.China \\ ahjxlcj2006@sina.com, b124854741@qq.com, c 65696787 @qq.com, djmsuzyx@163.com \\ * Author for correspondence :ZHANG Yun Xiang
}

Keywords: Herbal harvesting machine. Vibration digging shovel. 3D modeling. Motion simulation.

\begin{abstract}
Design process of long roots Chinese herbal medicine harvester is analyzed,3D solid modeling based on Pro/E for the herbal medicine harvester is made.Virtual assembly for harvest using Pro/E assembly module,also with movement simulation and analysis for it's key components is made in this paper. All of above provides reference and basis for physical prototype implementation of Chinese herbal harvester machine,and the key components are optimized,the maximum stress mainly distributed in the junction of digging shovel straight and bevel,edge is determined ,with the value is $0.53 \mathrm{MPa}$.
\end{abstract}

\section{Introduction}

Our country as a big cultivating and exporting country for Chinese herbal medicine,1000000 tons herbals is exported every year.All kinds of Chinese herbal medicine mainly rely on artificial cultivation, especially such as astragals, windbreak,licorice and so on,as mainly long root Chinese herbal medicine export, has a large exports volume.At present,our country medicine cultivating area already amounts to over 2500000 mus.But still far can not meet the needs of the international market. Its bottleneck problem for development and expanding cultivation of Long-roots mining harvest is with large amount of labor employment,At present,it's long-roots is mainly artificial digging or artificial picking after simple machinery mining. High labor intensity, low efficiency, high loss rate of harvest, low medicinal material quality, the economic benefits of the farmer is seriously influenced,also with greatly restricts to the cultivation of Chinese herbal medicine industry development,So It is urgent to research and develop Chinese herbal medicine machinery. Especially in the way of Long-roots herbal harvesting machinery. Because of the physical prototype in traditional design has long cycle,higher cost disadvantages, therefore, from the perspective of analysis and solution for harvesting machine overall performance and its related problems,during the long roots herbal harvesting machine design,Pro/E software is used to construct a virtual prototype model instead of physical prototype in this article,accost savings and loss time for the physical prototype development is provided.

\section{Harvesting process and working principle of long-roots herbal harvester}

The design of Long-roots herbal harvester in this paper can complete in one time separating, mining, medicine soil separation and placement and other harvest technology,Structure diagram as shown in figure 1.The whole machine is mainly composed of a machine frame,the seedling separating device,vibration shove,clamping mechanism, a hydraulic motor,coulter,The three point suspension in front part of the machine frame is connected with a tractor,the whole machine is driven by a tractor to 
be forward. The seedling separating device located in the front of the machine is used for Chinese herbal medicine collecting,Coulter is used to cut the soil into strips, at the same time, it can cut medicinal image away from two sides,In order to reduce the soil resistance in lifting process.Vibration digging shovel is the most important component of Long-roots herbal harvester,It's central is a flat piece with side bending,Its working surface and the horizontal surface maintains a $10^{\circ} \sim 12^{\circ}$ operation angle,This helps to lift herbals using it's central flat portion in cutting Chinese herbal medicine rhizomes.And soil on mining shovel can be outflow from its sides bending,missing,This can greatly reduce the resistance of soil.Digging shovel amplitude can be achieved by the different assembly locations of two eccentric shafts. Hydraulic motor is connected with the clamping strip assembly shaft to drive the clamping strip assembly to be into operation. Clamping strap assembly is mounted on the frame,using for pulling the herbals roots after the digging shovel cutting them and automatically strip-shaped lying.

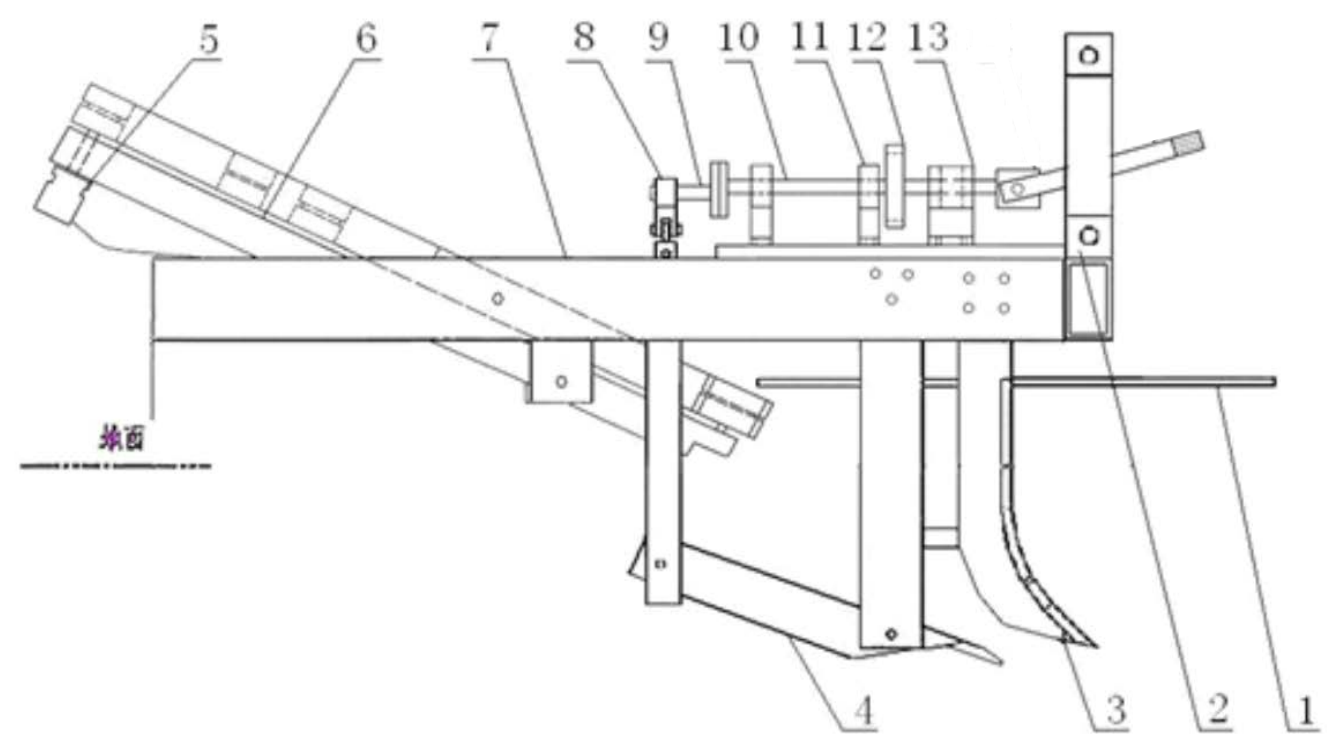

(1)Seedling separating device;(2)Suspension bracket;(3)Coulter;(4)Vibration digging shove;(5)Hydraulic motor; (6)Clamping strip assembly;(7)Rack;(8)Lug assembly;(9、10)Eccentric shaft;(11)Eccentric shaft bracket ;

(12)sprocket wheel;(13)Transmission shaft bracket

Fig. 1 Schematic diagram of Long-roots herbal harvester

\section{3 herbal harvesting machine 3D solid modeling}

This paper uses the Pro/E software to give a solid model for the herbal harvester. Modeling with the bottom-up design concept.First establishing entity model for the parts,then the parts virtual assembly into whole machine,when parts modeling under the situation of not affecting its harvest function,the basic characteristics of structural parts should be as simple as possible.also with parametric problems of the parts into consideration.This design mainly adapts geometry size for controlling 3D model and topological relation to design parameters.After all parts of the three-dimensional solid modeling completing,according to the machine design,a series of assembly for parts and parts, parts and whole machine,is finished. Basic idea for assembly is to use the space location relation of different parts in assembly, to bind them together with the sequence of from inside to outside, from front to back,from small to large. and with pin connection, fixed connection to complete virtual assembly.Chinese herbal medicine harvester virtual assembly model as shown in figure 2. 


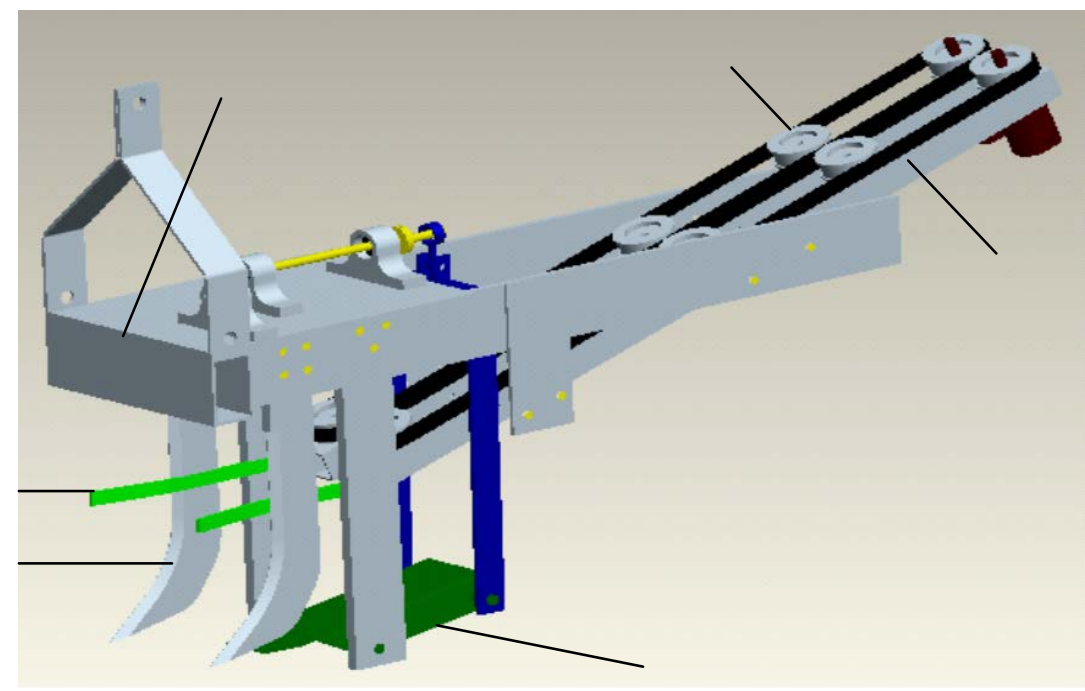

(1)Nearside divider;(2)Coulter;(3)Vibration digging shovel;(4)Vibration digging shovel clamp belt assembly;

(5)Hydraulic motor;(6)Driving wheel;(7)Lug assembly;(8)Sprocket wheel;(9)Eccentric shaft bracket;

(10)Eccentric shaft;(11)Machine frame;(12)Suspension rack

Fig. 2 Herbal harvester virtual assembly drawing

\section{Analysis for the simulation of mechanism motion}

Using the Pro/Mechanical motion analysis module,this paper gives a movement simulation for assembled herbal harvester model.By running mechanism analysis $\rightarrow$ analysis of playback $\rightarrow$ playback and analysis results, The whole process of motion simulation is preserved into video files, and the result of simulation is formed on the screen with the form of animation.

Interference can be checked using "global interference" functions in the analysis of this design. Timely the parts and assembly can be modificated,until not generating interference,at the same time making the movement into coordination.

In this paper, basing on Chinese herbal medicine harvester working device dynamic simulation, simulation analysis for the key components vibration-deep-digging-shovel is given.The relationship between motion track and time in a certain digging time is analyzed for the spade tip (as shown in figure 3)of vibration deep digging shovel working device The analysis results as shown in figure 4.

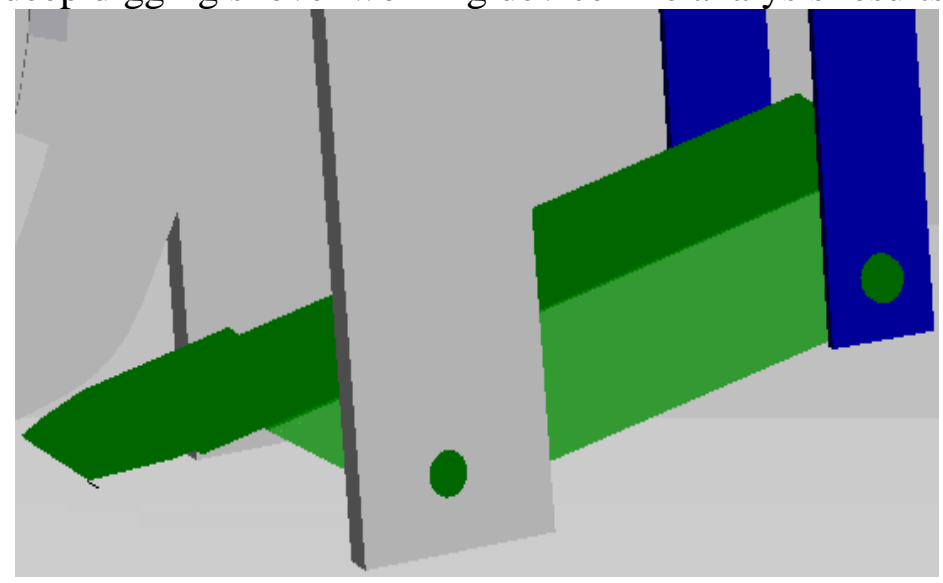

Fig.3 Deep digging shovel 


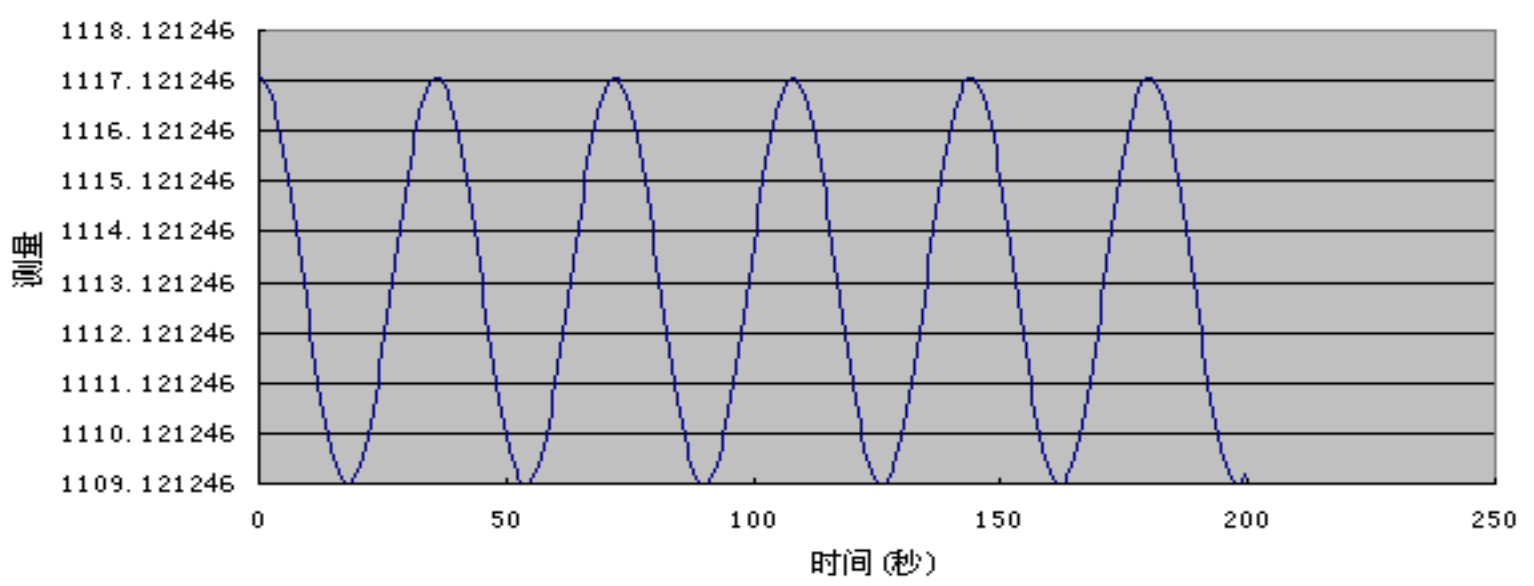

Fig.4 Deep digging shovel point trajectory

Vibrating deep digging shovel tip during working hours through akes regular up-down vibration at a certain speed by the power the lug welding assembly transmits. The vibration of shovel make soil vibrating,and at the same time can cut Chinese herbal 's roots away to achieve the purpose of harvesting herbs.

\section{Static analysis of digging shovel}

Static analysis is mainly to solve the structure stress,displacement and its distribution law,to find out the maximum value of stress and displacement,so that we can find out the dangerous section of the structure to determine if it's bearing capacity can meet the requirements or not.

First drawing a digging shovel simplified shape,after definition material properties in he ANSYS, freely mesh.In this paper the plate's material is 45 steel,the material properties (Young's modulus,Poisson's ratio,density,thermal expansion factor) as shown in figure 5.In the X,Y,Z three directions,translational and rotational is restraint, Duing to the digging shovel bottom surface $100 \mathrm{~mm}$ range is a welding part,So free- degree of translational and rotational for the portion of digging shove is all detrained to be 0,On the digging shovel front,loading stress $40 \mathrm{~N}$ is applied,Start the Pro/MECHANICA finite element analysis module. The system uses Auto GEM (automatic mesh partition) tools to finish the automatic generation of finite element mesh, And mesh optimization, The entity types of units is final generated,shown in figure 6 .

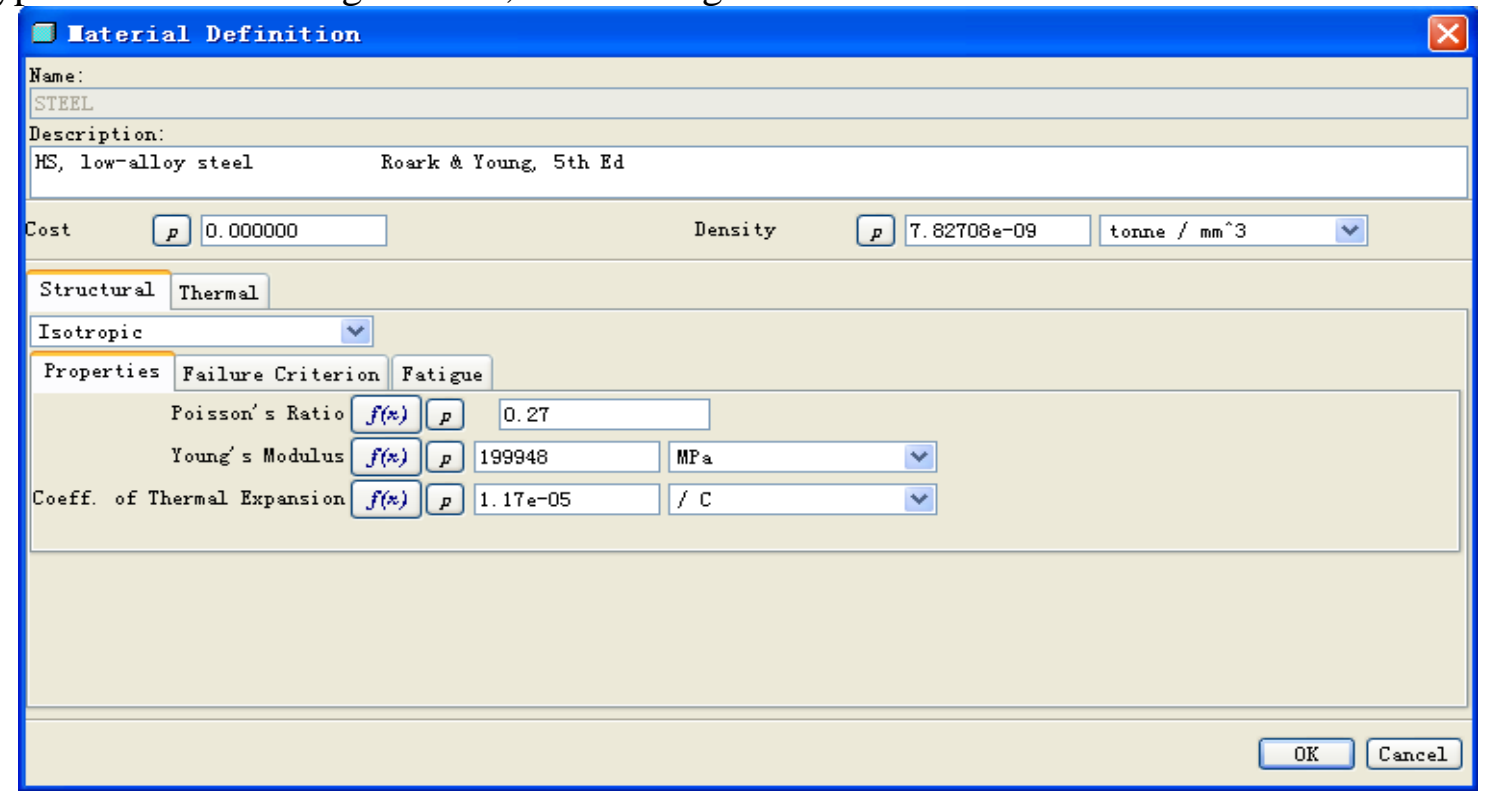

Fig.5 Definition of material physical properties 


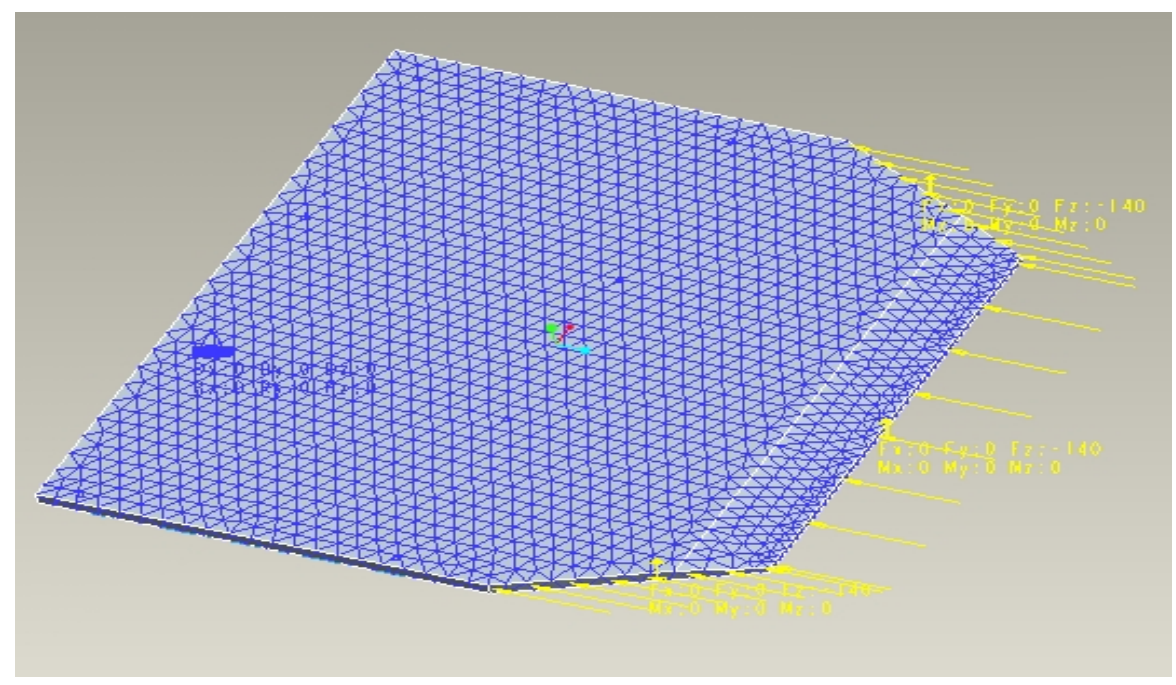

Fig.6 Digging shovel automatic mesh partition

Without considering the inertia and damping effect,We make use of the single channel adaptive convergence way of Pro/MECHANICA module to give a static analysis and solution on herbal harvesting machine digging shovel,At the same time the equivalent stress nephogram (as shown in figure 7) and a beveled edge stress nephogram is finally (as shown in Figure 8)achieved.

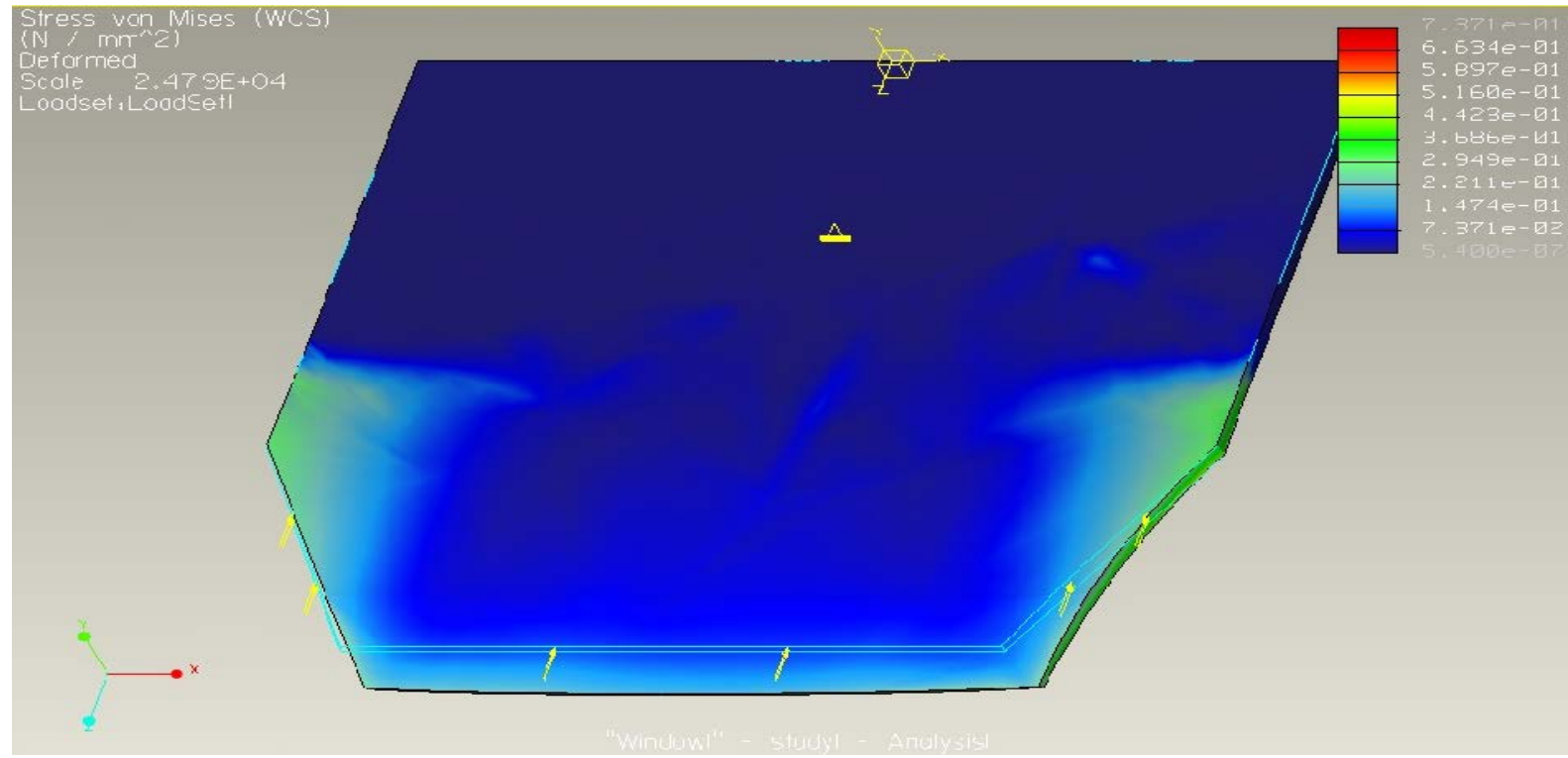

Fig. 7 Stress nephogram of digging shove

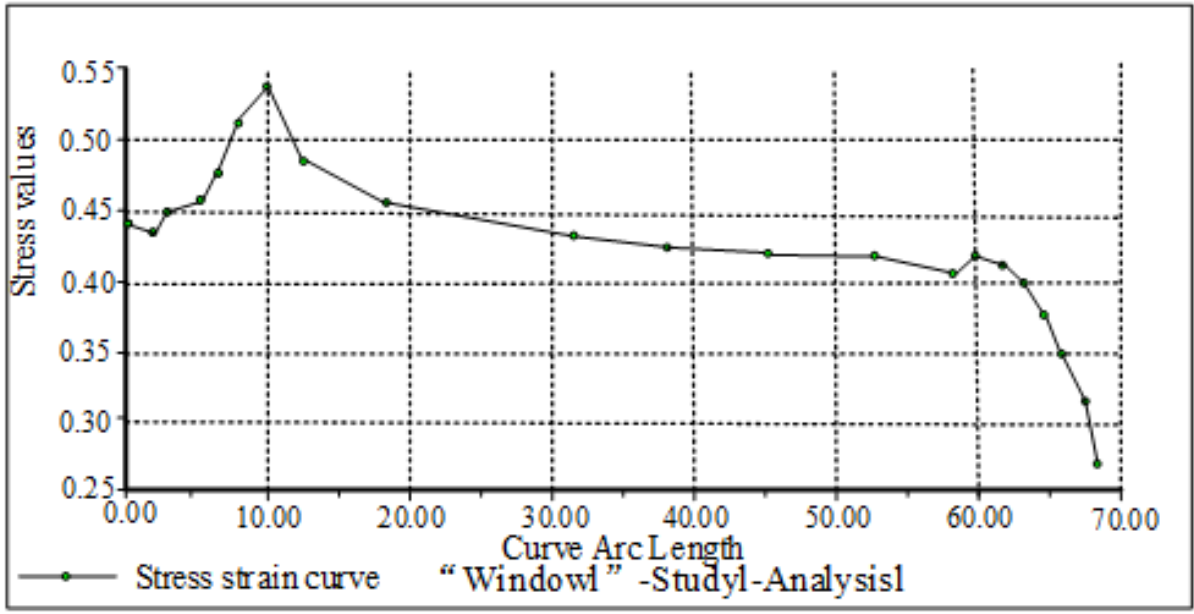

Fig.8 Edge stress analysis of digging sholve 
Figure 7 shows that the maximum stress is mainly distributed in the junction of digging shovel straight and bevel edge.From the graph 8 shows,maximum stress of $0.53 \mathrm{MPa}$ is resulted from the location of $10 \mathrm{~mm}$ near by the bevel edge

\section{Conclusions}

Long-roots herbal harvester virtual prototype is designed by using of Pro/E virtual development platform.The Chinese herbal medicine harvest technology is realized by theory.The kinematics simulation and analysis of the virtual prototype work mechanism is provided,the movement trajectory and the maximum stress value of key components of vibration digging shovel is also given,All of above provides reference and basis for trial production of long roots herbs physical prototype.

Funded projects:This work is supported by Plan Project of Youth Foundation of jiamusi University

(Lq2013-032) and College students' innovative entrepreneurial training project (2014xj05)

\section{References}

[1] Dj.M. Maric, P.F. Meier and S.K. Estreicher: Mater. Sci. Forum Vol. 83-87 (2012), p. 119

[2] M.A. Green: High Efficiency Silicon Solar Cells (Trans Tech Publications, Switzerland 2006).

[3] Y. Mishing, in: Diffusion Processes in Advanced Technological Materials, edtied by D. Gupta Noyes Publications/William Andrew Publising, Norwich, NY (2012), in press.

[4] G. Henkelman, G.Johannesson and H. Jónsson, in: Theoretical Methods in Condencsed Phase Chemistry, edited by S.D. Schwartz, volume 5 of Progress in Theoretical Chemistry and Physics, chapter, 10, Kluwer Academic Publishers (2013).

[5] R.J. Ong, J.T. Dawley and P.G. Clem: submitted to Journal of Materials Research (2013)

[6] P.G. Clem, M. Rodriguez, J.A. Voigt and C.S. Ashley, U.S. Patent 6,231,666. (2011)

[7] Information on http://www.weld.labs.gov.cn 